\title{
Intellectual authorities and hubs of Green Chemistry
}

\author{
Autoridades e hubs intelectuais da Química Verde
}

\author{
Leonardo Victor MARCELINO1 (iD) 0000-0002-2684-5656 \\ Adilson Luiz PINTO2 (iD) 0000-0002-4142-2061 \\ Carlos Alberto MARQUES 1 (D) 0000-0002-4024-7695
}

\begin{abstract}
Green Chemistry is a self-organized movement of chemists intended to prevent and minimize the use and production of dangerous substances and processes. The current output and growing rate of the field hinders descriptive analysis of its contents, innovations (if any), and dynamics. Therefore, new methodologies must be sought. This research aims at broadening the understanding on the structure of Green Chemistry by pointing out its intellectual hubs (researchers important to the spread and consolidation of knowledge) and its intellectual authorities, the sources of that knowledge. Documents $(N=14,142)$ either containing the term "green chemistry" or published in the Green Chemistry Journal and the Green Chemistry Letters and Reviews between 1990 and 2017 were analyzed by co-citation and network analysis. Sixteen clusters were grouped in six big specialties, from which 14 hubs and 21 authorities were found. Results corroborate previous analyses of the field, but this research has the advantage of stemming from the dynamics of scientific production, rather than from previously defined qualitative categories of the field itself.
\end{abstract}

Keywords: CiteSpace. Co-citation analysis. Green chemistry.

\section{Resumo}

A Química Verde é um movimento auto-organizado de químicos para prevenir e minimizar o uso e a produção de substâncias e processos perigosos. O atual número de publicações e a taxa de crescimento do campo dificultam a análise qualitativa de seu conteúdo, inovações (se houver) e dinâmica, portanto, novas metodologias devem ser estudadas. Esta pesquisa visa ampliar o entendimento sobre a estrutura da Química Verde apontando seus hubs intelectuais (pesquisadores importantes para a difusão e consolidação do conhecimento) e suas autoridades intelectuais, as fontes desse conhecimento. Documentos ( $N=14.142)$ contendo o termo "química verde" ou publicados no Green Chemistry Journal e no Green Chemistry Letters and Reviews entre 1990 e 2017 foram analisados por cocitação e análise de rede. Dezesseis clusters foram agrupados em seis grandes especialidades, das quais foram encontrados 14 hubs e 21 autoridades. Os resultados corroboram análises anteriores da área, mas esta pesquisa tem a vantagem de partir da dinâmica da produção científica, e não de categorias qualitativas da própria área previamente definidas.

Palavras-chave: CiteSpace. Análise de cocitação. Química verde.

\footnotetext{
1 Universidade Federal de Santa Catarina, Centro de Ciências da Educação, Departamento de Metodologia de Ensino. R. Eng. Agronômico Andrei Cristian Ferreira, s/n, 88040-900, Florianópolis, SC, Brasil. Correspondência para/Correspondence to: C.A. MARQUES. E-mail: <carlos.marques@ufsc.br>.

2 Universidade Federal de Santa Catarina, Centro de Ciências da Educação, Departamento de Ciências da Informação. Florianópolis, SC, Brasil.

Support: Conselho Nacional de Desenvolvimento Científico e Tecnológico (no 141131/2018-7) e Comissão de Aperfeiçoamento de Pessoal de Nível Superior (no 88881.189651/2018-0).

Article based on the thesis of L.V. MARCELINO, entitled "Os tipos de racionalidade na química verde e suas relações com o ensino". Universidade Federal de Santa Catarina, 2020.

Received on July 16, 2020, final version resubmitted on October 30, 2020 and approved on November, 4, 2020.

Como citar este artigo/How to cite this article

Marcelino, L. V.; Pinto, A. L.; Marques, C. A. Intellectual authorities and hubs of Green Chemistry. Transinformação, v. 32, e200031, 2020. https://doi. org/10.1590/2318-0889202032e200031
} 


\section{Introduction}

Environmental impacts, big industrial accidents, and growing public awareness regarding those events have led chemists to reflect on the influences of their practices, and look for more responsible actions by their professional community. Such is the case of Green Chemistry (GC), a self-regulatory movement started by chemists around 1990, which involves the academia and industries in designing and implementing more benign practices (Anastas et al., 2016). Green Chemistry appears as a proactive, prevention-based approach, minimizing and avoiding (if possible) the intrinsic danger and waste generation in chemical processes (Poliakoff, 2002), and following the Pollution Prevention Act (United States Environmental Protection Agency, 1990).

Strategies of GC are based on twelve principles of design, formulated in 1998, and largely impacting the consolidation and expansion of green practices (Anastas; Warner, 1998; Anastas et al., 2018): (1) Waste Prevention; (2) Atom Economy; (3) Less Hazardous Chemical Synthesis; (4) Designing Safer Chemicals; (5) Safer Solvents and Auxiliaries; (6) Design for Energy Efficiency; (7) Use of Renewable Feedstocks; (8) Reducing Derivatives; (9) Catalysis; (10) Design for Degradation; (11) Real Time Pollution Prevention; and (12) Inherently Safer Chemistry for Accident Prevention.

After almost three decades, advances of GC for groundbreaking chemical practices are still being discussed, usually from the perspective of its principles in a qualitative manner (Clark et al., 2014; Anastas et al., 2016, 2018; Ivanković, 2017). Nevertheless, GC output has grown over 2.000\% from 1998 to 2018, as search on the Web of Science shows, hindering qualitative analyses of the field. Research that systematizes the knowledge already produced and points to more effective means of selecting information is needed. Recent studies (Marcelino; Marques, 2019; Marcelino; Pinto; Marques, 2020a) analyzed research topics of GC by co-citation analysis, using objective, selforganizing parameters to classify the academic output into specialties, deviating from previous classification based on the 12 Principles and a priori categories.

Previous publications analyze the thematic structure of the field (Marcelino; Marques, 2019; Marcelino; Pinto; Marques, 2020a), but its evolution and main actors are still missing from the debate. The purpose of this research is to broaden the understanding on GC research structure, by pointing the researchers that have most contributed to its growth, spread, and consolidation (its intellectual hubs), and the authors upon whose knowledge they have drawn (intellectual authorities). This is done by adapting the concept of hubs and authorities (Kleinberg, 1999) to multilayered networks that represent a co-citation analysis, contributing to the field of metric studies of information, a starting point and one of the domains of Information Science (Hjørland, 2005; Araújo, 2009).

\section{Hubs and intellectual authorities}

According to Jon Kleinberg, an authority is a node that provides content of relevance in a network and a hub is a node that selects, groups, and disseminates information across the network (Kleinberg, 1999). Kleinberg's algorithm is based on mutual recursion, so that, in a given network, an important hub connects to important authorities, and vice versa (Zhong et al., 2019; Majó-Vázquez et al., 2020).

This research used CiteSpace, a software for analyzing and representing the dynamics of a knowledge domain in terms of scientific specialties. Each specialty is defined as a cluster in a network that relates a set of co-cited papers (the intellectual base), and the papers that promote those co-citations (the research front) (Chen, 2006). The final network is created as the interpolation of several smaller networks across time, enabling the analysis of the evolution of the knowledge domain.

In CiteSpace, the network of co-cited papers (intellectual base) is associated to a set of co-citing papers (the research front). The research front forms an invisible network over the intellectual base, creating two sources of 
information that render Kleinberg's analysis of hubs and authorities much more complex, and an alternative ought to be developed. Recent research investigates multilayered networks and their hubs and authorities (Berger-Wolf; Chawla, 2019), and so does this paper.

This research considers that nodes in the research front with a high degree of connection, grouping the intellectual base around a research theme and disseminating information throughout the scientific community, act as hubs. Hub behavior is given by two indicators: its Coverage (Cov) value and Global Citation Score (GCS). Coverage indicates how much a certain author contributes to grouping information and shaping a research/specialty front. The GCS is the amount of citations an author has received from the entire scientific community, and indicates the role of the researcher in disseminating the research/specialty front.

Nodes from the intellectual base that introduces relevant information in the network act as intellectual authorities, providing the concepts, methodologies, and techniques necessary for the existence of a specialty. Three indicators (Chen, 2006, 2017) may be used for identifying intellectual authorities: Citation Frequency (CF), Citation Burstiness (CB), and Betweenness Centrality (BtC). CF is the amount of co-citations an author or document received within the selected sample. Unlike GCS, which considers all the citations received by a document, CF is an indicator of the recognition of the paper or author by green chemists, enabling inferences on the recognition of a given specialty. Citation Burstiness measures a sudden increase in the number of citations of a document/author, and is an indicator of the degree of innovation introduced in the field of knowledge, which generates sudden interest in a given subject. Betweenness Centrality is the ability of a work/author to transit among various specialties, promoting interaction and information exchange. Elements with high BtC fill gaps in the structure of knowledge, and act as bridges among different research topics.

Local Citation Score (LCS), Number of Papers (NP), CF, BtC, and CB values are all calculated for each author by the simple sum of the individual values of each metric for the papers of this author. Total GCS is the sum of GCS values of different papers by the same author. Nevertheless, a given author's total coverage is measured by the quotient of the number of papers this author cites in the intellectual base divided by the total number of papers in the intellectual base of a specialty. For the temporal analysis of hubs, the value of coverage is given as the number of co-cited papers by that author (Cov-N), not as a quotient.

\section{Methodological Procedures}

All data was collected in May 2018 in the Web of Science database (Core Collection, indexes: SCI-EXPANDED, SSCl, A\&HCl, CPCI-S, CPCI-SSH, ESCI) from 1990 (the decade in which GC emerges) (Anastas et al., 2016) to 2017 (the last full year at the time of analysis) (Table 1). Documents were selected for containing references, such as: papers, reviews, proceedings papers, and book chapters (henceforth papers). The term "green chemistry" was searched in titles, keywords, and abstracts, thus indicating explicit affiliation to GC. All texts published in the Green Chemistry Journal and the Green Chemistry Letters and Reviews were also selected, as these are the specialized GC journals with the highest output according to Web of Science, and their texts do not always use the descriptor "green chemistry" in their titles, abstracts, and keywords.

A final set of 14,142 different records (duplicates excluded) was selected as input data, including 8,586 records with the term "green chemistry" and 6,004 published in specialized journals. This data was analyzed by CiteSpace (version 5.2.R1.3.9.2018), considering: Look Back Year (LBY): -1; Time Slice: 3 years (1990-2017); Node types: Cited reference; Top N.: 100. These parameters were chosen for their best results in Modularity Q and Silhouette values (Marcelino; Pinto; Marques, 2020b). Other parameters followed default program settings. After the network was created, the algorithm was applied for the generation of clusters, the themes of which were inferred from the titles and abstracts of the papers in the research front of each cluster. 
Table 1. Methodological steps.

\begin{tabular}{|c|c|c|}
\hline Process (local) & Parameters & Results \\
\hline \multirow{6}{*}{$\begin{array}{l}\text { Data Retrieval } \\
\text { (Web of Science) }\end{array}$} & Topic Search: & \\
\hline & • Term: "green chemistry" & 8,586 documents \\
\hline & - Topics: titles, abstracts, keywords & 14142 different documentc \\
\hline & Specialized journals: & 14,142 aliterent documents \\
\hline & - Green Chemistry & 6,004 documents \\
\hline & - Green Chemistry Letters and Reviews & \\
\hline \multirow{5}{*}{$\begin{array}{l}\text { Data Selection } \\
\text { (CiteSpace) }\end{array}$} & Co-citation Analysis: & Research Front: 184 documents \\
\hline & - Look back year: -1 & \multirow{4}{*}{ Intellectual Base: 368 documents } \\
\hline & - Time slice: 3 years & \\
\hline & - Node type: cited references & \\
\hline & - Top N.: 100 & \\
\hline \multirow{10}{*}{$\begin{array}{l}\text { Data Analysis } \\
\text { (MS Office Excel) }\end{array}$} & Authors in Research Front: & \multirow{5}{*}{ Intellectual Hubs } \\
\hline & - Cov and Cov-N & \\
\hline & - GCS & \\
\hline & - LCS & \\
\hline & - N BSpec & \\
\hline & Authors in Intellectual Base: & \multirow{5}{*}{ Intellectual Authorities } \\
\hline & $\bullet N P$ & \\
\hline & - $\mathrm{BtC}$ & \\
\hline & - $\mathrm{CB}$ & \\
\hline & - N BSpec & \\
\hline
\end{tabular}

Source: Elaborated by the authors (2020).

Note: BtC: Betweenness Centrality; CB: Citation Burstiness; CF: Citation Frequency; Cov: Quotient of papers co-cited by author; Cov-N: Number of papers co-cited by author; GC: Green Chemistry; GCS: Global Citation Score; LCS: Local Citation Score; N BSpec: Number of participations in different Big Specialties; NP: Number of co-cited papers; Spec: Specialty.

In the Web of Science database, bibliometric information of the papers in the research fronts (184 different documents) and intellectual base (368 different documents) was retrieved to obtain the complete names of authors and co-authors. The authors' and co-authors' names were standardized to avoid duplicates, especially those that were fully abbreviated without punctuations and spaces. Accumulated values of specific indicators were attributed to each author, considering the whole period of analysis (1990-2017), and in periods of six years for analyzing the historical development of the authorities and hubs.

The analysis (Noyons, 1999; Liao et al., 2017) was validated by considering the internal evaluation parameters of the network (Modularity Q and silhouette) and peer recognition (comparison with previous qualitative description of the field made by renowned researchers) (Anastas et al., 2016; Royal Society of Chemistry, 2016). The complete research data can be accessed in an open repository (Marcelino; Pinto; Marques, 2020b).

\section{Results and Discussion}

Co-citation analysis by CiteSpace generated six main research trends (big specialties), considering the proximity of themes and methodologies among 16 clusters. Each specialty was defined as the relationship between a time-variant network of co-cited papers (i.e., an intellectual base), and the papers that promote co-citations in the network (the research front) (Chen, 2006, 2017). Figure 1 (a) presents papers in the intellectual base as nodes with sizes proportional to the $C F$, as the size of the red dots are related to $C B$. The edges signify the co-citation, and the colors denote the year the co-citation was made, from dark purple (1996) to light yellow (2017). 


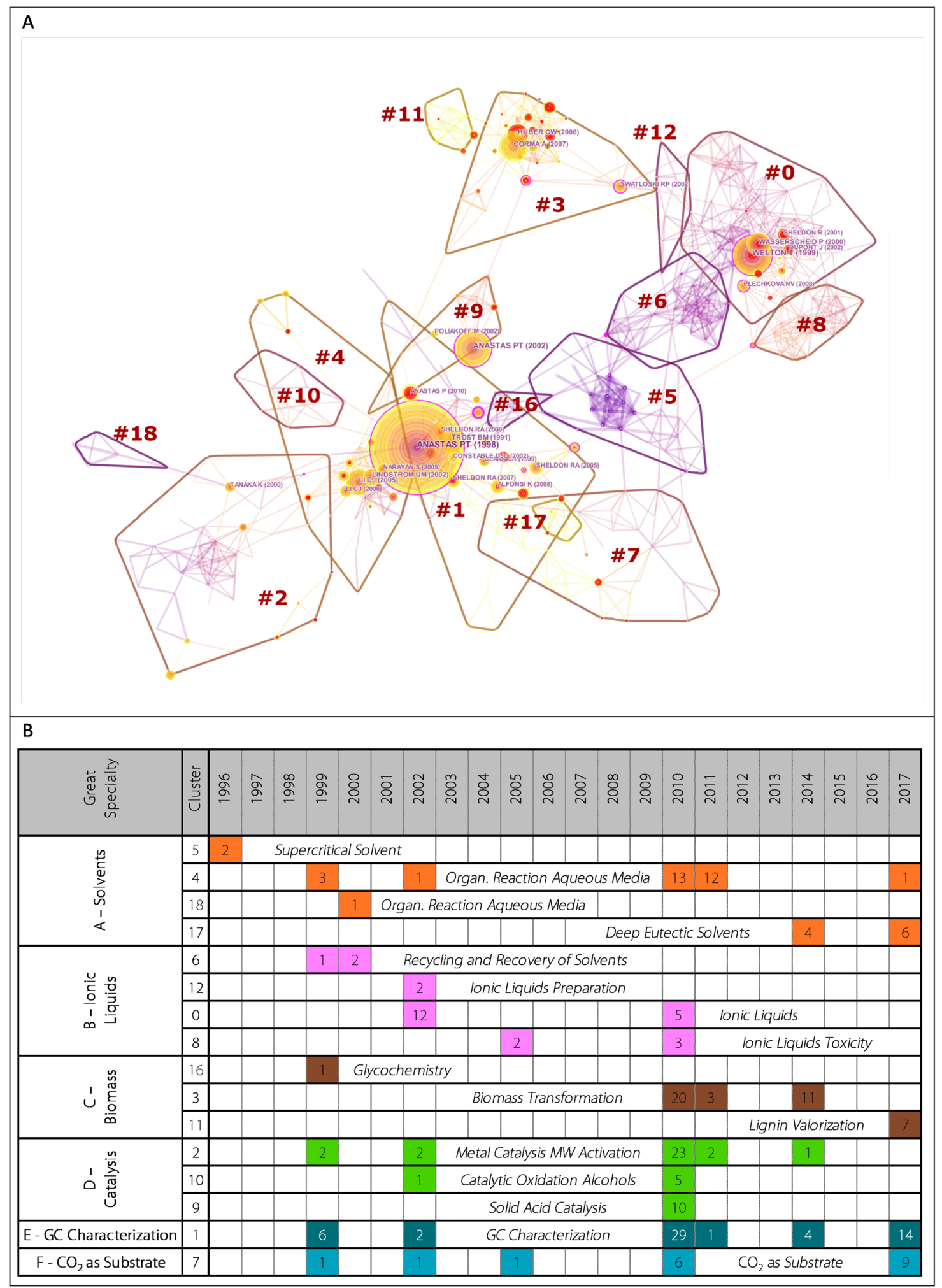

Figure 1. Co-citation network of Green Chemistry (1990-2017).

Source: Elaborated by the authors (2020).

Note: (a) Co-citation network of Green Chemistry and their specialties (clusters); (b) Size and years of activities of scientific specialties of Green Chemistry. \#: Cluster; $\mathrm{CO}_{2}$ : Carbon Dioxide; GC: Green Chemistry; Organ:: Organic; MW: Micro-wave. 


\section{Scientific specialties of Green Chemistry}

Figure 1(b) presents the 16 specialties grouped in their thematic superclusters, containing the year of appearance of each of the research fronts and their extension until the last appearance, as well as indicating the number of works produced within it in that interval. According to Figure 1(b), the first specialty to take shape in 1996 (cluster \#5 - Supercritical Solvents) deals with supercritical fluids as solvents, and introduces the first supercluster: A - Solvents. This great theme also brings together specialties \#4 and \#18 on Organic Reactions in Aqueous Media and cluster \# 17 - Deep Eutectic Solvents, all addressing the issue of solvents. In total, Supercluster A has 43 papers on the research front, distributed from 1996 to 2017.

In 1999, other five superclusters are formed (Figure 1b), demonstrating the impact of the Green Chemistry Journal (created on 1999) on the production of knowledge in GC. Clark (2001) also highlights the growth in the number of congresses, acceptance by the industry, and growth of output during this period. Big specialty B - lonic Liquids begins with specialty \#6 - Recycling and Solvent Recovery, which brings in its intellectual base the seeds of the use of ionic liquids as more environmentally benign processes, addressed in the following years by clusters $\# 12$ - Preparation of lonic Liquids, \#0 - Ionic Liquids and \#8 - Toxicity of lonic Liquids. This supercluster has 27 texts in its research front, with focus of interest between 1999 and 2010.

Supercluster C - Biomass starts with specialty \#16 - Glycochemistry, but it will only have another research front as of 2010, with specialties \#3 - Biomass Transformation and \#11 - Lignin Valorization. This great specialty has 42 members in its research front, extending until 2017.

Supercluster D - Catalysis began in 1999 with specialty \#2 - Metal Catalysis with Microwave Activation. This theme is continued in 2010 by clusters \#10 - Catalytic Oxidation of Alcohols and \#9 - Solid Acid Catalysts. It is a supercluster that has 46 members in its research front and has a research front formed by 2014.

Big specialty E - GC Characterization contains only cluster \#1 (of the same name), comprising articles that discuss the nature, advances, and limits of GC. It is the largest specialty with 56 members in its research front, which was to be expected, since this is an analysis of Green Chemistry itself. It remains active in 2017.

Big specialty $\mathrm{F}-\mathrm{CO}_{2}$ as Substrate contains only the homonymous cluster \#7. It is the smallest of the great themes of GC, with 18 papers in its research front, but it has a research front developed until 2017.

\section{Intellectual hubs and authorities of specialties}

Table 2 and Table 3 register the authors classified as intellectual hubs and authorities. Hubs were chosen in terms of large output and high contributions to co-citations in the research fronts. Intellectual authorities were selected by their highest number of papers in the intellectual base, and accumulated CF, CB, and BtC, demonstrating their importance in providing support to the works in the big specialty.

In the selection of hubs and authorities of big specialty A - Solvents, it is important to highlight research on organic reactions in aqueous medium (cluster \#18), as it is one of its most recognized subjects of study, and has the largest research front.

Considering big specialty B - Ionic Liquids, the recurrence of authors in the research front and intellectual base demonstrates the internal cohesion of this big specialty; additionally, the fact that this big specialty holds the highest CB values indicates great interest and commitment among its researchers, especially until 2009.

In big specialty C - Biomass, James Dumesic has a very important role as an intellectual authority, as he is the author who publishes the most, and whose texts have aroused the interest of the scientific community (high CB and (F). Paul Anastas is greatly influential in the specialty, despite his output consisting of more general papers on GC. 
Table 2. Main authors in the research front of big specialties of Green Chemistry (1990-2017).

\begin{tabular}{|c|c|c|c|c|c|c|c|c|}
\hline \multirow{2}{*}{ Big Spec } & \multirow{2}{*}{ Author } & Cov Spec & Total Cov & GCS Spec & Total GCS & LCS Spec & Total LCS & NBSp \\
\hline & & \multicolumn{7}{|c|}{$n$} \\
\hline \multirow{5}{*}{ A - Solvents } & Cadierno, V. & 0.2411 & 0.0527 & 245 & 397 & 5 & 7 & 2 \\
\hline & Francos, J. & 0.1851 & 0.0417 & 200 & 352 & 4 & 6 & 2 \\
\hline & Borkowsky, S.I. & 0.1667 & 0.0327 & 79 & 79 & 1 & 1 & 1 \\
\hline & Brown, G.H. & 0.1667 & 0.0327 & 79 & 79 & 1 & 1 & 1 \\
\hline & Burk, M.J. & 0.1667 & 0.0327 & 79 & 79 & 1 & 1 & 1 \\
\hline \multirow{5}{*}{ B - Ionic Liquids } & Rogers, R.D. & 0.295 & 0.090 & 612 & 612 & 4 & 4 & 1 \\
\hline & Holbrey, J.D. & 0.231 & 0.070 & 584 & 584 & 3 & 3 & 1 \\
\hline & Reichert, W.M. & 0.221 & 0.067 & 594 & 594 & 3 & 3 & 1 \\
\hline & Swatloski, R.P. & 0.221 & 0.067 & 594 & 594 & 3 & 3 & 1 \\
\hline & Seddon, K.R. & 0.201 & 0.061 & 1.240 & 1.240 & 4 & 4 & 1 \\
\hline \multirow{5}{*}{ C-Biomass } & Alonso, D.M. & 0.202 & 0.027 & 1.061 & 1.061 & 2 & 2 & 1 \\
\hline & Dumesic, J.A. & 0.202 & 0.027 & 1.061 & 1.061 & 2 & 2 & 1 \\
\hline & Takagaki, A. & 0.202 & 0.038 & 204 & 230 & 2 & 3 & 2 \\
\hline & Hara, M. & 0.182 & 0.071 & 291 & 485 & 4 & 7 & 2 \\
\hline & Renders, $\mathrm{T}$. & 0.163 & 0.022 & 14 & 14 & 2 & 2 & 1 \\
\hline \multirow{5}{*}{ D - Catalysis } & Hara, M. & 0.279 & 0.0707 & 194 & 485 & 3 & 7 & 2 \\
\hline & Liang, X.Z. & 0.264 & 0.0438 & 22 & 22 & 3 & 3 & 1 \\
\hline & Qi, C.Z. & 0.264 & 0.0438 & 22 & 22 & 3 & 3 & 1 \\
\hline & Yamaguchi, D. & 0.197 & 0.0381 & 63 & 126 & 2 & 4 & 2 \\
\hline & Varma, R.S. & 0.181 & 0.0434 & 2.060 & 3.938 & 4 & 6 & 3 \\
\hline \multirow{5}{*}{ E - GC Characterization } & Anastas, P. & 0.19 & 0.071 & 1.561 & 5.198 & 3 & 9 & 5 \\
\hline & Sheldon, R.A. & 0.13 & 0.049 & 433 & 1.402 & 2 & 4 & 3 \\
\hline & Clark, J.H. & 0.13 & 0.016 & 625 & 625 & 1 & 1 & 1 \\
\hline & Lawrenson, S. & 0.11 & 0.013 & 18 & 18 & 2 & 2 & 1 \\
\hline & North, M. & 0.11 & 0.022 & 18 & 595 & 2 & 3 & 2 \\
\hline \multirow{5}{*}{$\mathrm{F}-\mathrm{CO}_{2}$ as Substrate } & Steinbauer, J. & 0.47 & 0.0432 & 34 & 53 & 4 & 7 & 2 \\
\hline & Werner, T. & 0.47 & 0.0432 & 34 & 53 & 4 & 7 & 2 \\
\hline & Buttner, $\mathrm{H}$. & 0.25 & 0.0215 & 23 & 31 & 2 & 3 & 2 \\
\hline & Longwitz, L. & 0.25 & 0.0240 & 10 & 20 & 2 & 4 & 2 \\
\hline & Wulf, C. & 0.25 & 0.0215 & 23 & 31 & 2 & 3 & 2 \\
\hline
\end{tabular}

Source: Elaborated by the authors (2020).

Note: $\mathrm{CO}_{2}$ : Carbon Dioxide; Cov: Quotient of papers co-cited by author; GC: Green Chemistry; GCS: Global Citation Score; LCS: Local Citation Score; N BSpec: number of participations in different Big Specialties; Spec: Specialty.

The most outstanding authors in the research front of E - GC Characterization are Paul Anastas, Roger Sheldon, and James Clark, indicating that they are intellectual hubs, responsible for bringing together the discussion about what GC is and how to evaluate it, as well as spreading the principles and procedures of this field. The intellectual base of this specialty shows us that Sheldon and Clark are also leading intellectual authorities, developing research that provides important information for GC characterization.

\section{Intellectual hubs and authorities across specialties}

Here, we analyze possible hubs and authorities for GC as a whole, considering the specialties altogether. The 185 papers of the research front were published by 655 different authors, an average of 3.6 authors per work. The authors that publish in at least one third of the big specialties were assessed as potential hubs for the entire GC, acting across specialties. 
Table 3. Main authors in the intellectual base of specialties of Green Chemistry (1990-2017).

\begin{tabular}{|c|c|c|c|c|c|c|c|c|c|c|}
\hline \multirow[t]{2}{*}{ Big Spec } & \multirow[t]{2}{*}{ Authors } & NP A & Total NP & N BSpec & CB A & Total CB & $\mathrm{BtC} A$ & $\begin{array}{c}\text { Total } \\
\text { BtC }\end{array}$ & CFA & Total CF \\
\hline & & \multicolumn{9}{|c|}{$n$} \\
\hline \multirow{5}{*}{ A - Solvents } & Li, C.J. & 10 & 9 & 2 & 117.46 & 133.09 & 0.17 & 0.2 & 951 & 1.074 \\
\hline & Fokin, V.V. & 2 & 2 & 1 & 24.08 & 24.08 & 0.02 & 0.02 & 358 & 358 \\
\hline & Lindstrom, U.M. & 2 & 2 & 1 & 31.32 & 31.32 & 0.06 & 0.06 & 332 & 332 \\
\hline & Bienaymé, H. & 2 & 2 & 1 & 20.42 & 20.42 & 0.03 & 0.03 & 236 & 236 \\
\hline & Domling, A. & 2 & 2 & 1 & 19.66 & 19.66 & 0.02 & 0.02 & 216 & 216 \\
\hline \multirow{5}{*}{ B - Ionic Liquids } & Welton, T. & 8 & 7 & 2 & 136.34 & 152.53 & 0.18 & 0.18 & 831 & 869 \\
\hline & Seddon, K.R. & 17 & 17 & 1 & 228.41 & 228.41 & 0.31 & 0.31 & 774 & 774 \\
\hline & Wasserscheid, P. & 6 & 6 & 1 & 114.14 & 114.14 & 0.03 & 0.03 & 463 & 463 \\
\hline & Rogers, R.D. & 12 & 9 & 3 & 113.43 & 149.52 & 0.12 & 0.27 & 335 & 612 \\
\hline & Sheldon, R. & 23 & 4 & 5 & 92.15 & 275.84 & 0.06 & 0.5 & 313 & 1.718 \\
\hline \multirow{5}{*}{ C-Biomass } & Corma, A. & 3 & 5 & 2 & 67.29 & 92.1 & 0.08 & 0.08 & 717 & 772 \\
\hline & Iborra, S. & 3 & 3 & 1 & 67.29 & 67.29 & 0.08 & 0.08 & 717 & 717 \\
\hline & Dumesic, J.A. & 9 & 9 & 1 & 113.47 & 113.47 & 0.04 & 0.04 & 661 & 661 \\
\hline & Huber, G.W. & 5 & 5 & 1 & 66.23 & 66.23 & 0.01 & 0.01 & 556 & 556 \\
\hline & Velty, A. & 1 & 1 & 1 & 19.77 & 19.77 & 0.07 & 0.07 & 381 & 381 \\
\hline \multirow{5}{*}{ D - Catalysis } & Varma, R.S. & 7 & 9 & 2 & 86.48 & 118.59 & 0.16 & 0.21 & 341 & 426 \\
\hline & Anastas, P. & 6 & 9 & 2 & 85.36 & 115.73 & 0.28 & 0.46 & 1065 & 2.410 \\
\hline & Sheldon, R. & 6 & 23 & 5 & 26.64 & 275.84 & 0.02 & 0.5 & 221 & 1.718 \\
\hline & Loupy, A. & 5 & 5 & 1 & 70.51 & 70.51 & 0.02 & 0.02 & 148 & 148 \\
\hline & Polshettiwar, V. & 3 & 4 & 2 & 55.41 & 66.15 & 0.03 & 0.03 & 180 & 199 \\
\hline \multirow{5}{*}{ E-GC Characterization } & Sheldon, R. & 9 & 23 & 5 & 108.85 & 275.84 & 0.38 & 0.5 & 1.053 & 1.718 \\
\hline & Clark, J. & 6 & 8 & 3 & 14.52 & 48.86 & 0.05 & 0.05 & 253 & 384 \\
\hline & Trost, B.M. & 4 & 4 & 1 & 32.55 & 32.55 & 0.3 & 0.3 & 737 & 737 \\
\hline & Constable, D.J.C. & 4 & 4 & 1 & 27.43 & 27.43 & 0.12 & 0.12 & 475 & 475 \\
\hline & Curzons, A.D. & 4 & 4 & 1 & 27.43 & 27.43 & 0.12 & 0.12 & 475 & 475 \\
\hline \multirow{5}{*}{$\mathrm{F}-\mathrm{CO}_{2}$ as Substrate } & Anastas, P. & 3 & 9 & 2 & 30.37 & 115.73 & 0.18 & 0.46 & 1.345 & 2.410 \\
\hline & Sakakura, T. & 3 & 3 & 1 & 25.05 & 25.05 & 0.04 & 0.04 & 229 & 229 \\
\hline & Choi, J.C. & 2 & 2 & 1 & 12.18 & 12.18 & 0.04 & 0.04 & 167 & 167 \\
\hline & Yasuda, H. & 1 & 1 & 1 & 7.34 & 7.34 & 0.04 & 0.04 & 159 & 159 \\
\hline & Leitner, W. & 2 & 4 & 3 & 39.04 & 48.93 & 0.09 & 0.1 & 118 & 134 \\
\hline
\end{tabular}

Source: Elaborated by the authors (2020).

Note: BtC: Betweenness Centrality; CB: Citation Burstiness; CF: Citation Frequency; CO,: Carbon Dioxide; GC: Green Chemistry; N BSpec: number of participations in different Big Specialties; NP: number of co-cited papers; Spec: Specialty.

Anastas may be viewed as having great influence on the research fronts, taking $1 \%$ of all authorship positions. Paul Anastas and Nicolas Eghbali present papers that cover the largest number of big specialties (5), leaving out only specialty $\mathrm{F}-\mathrm{CO}_{2}$ as Substrate. It may be noticed that many of the authors presented in Table 2 are also listed among those who publish the most.

There are not many authors on the research front spreading big specialty B - Ionic Liquids among other specialties. This general articulation is made only by Anastas and Eghbali (Anastas; Eghbali, 2010) in a more general reference of GC, indicating that big specialty $B$ has researchers more focused on interacting among themselves and solving internal problems. Similarly, specialty $\mathrm{F}-\mathrm{CO}_{2}$ as Substrate is more directly related to big specialties A - Solvents, D - Catalysis and E - CG Characterization, as pointed earlier.

Cross-referencing the authors in the research front that publish the most, take part in several specialties, and possess high citation values may produce a group of researchers who take a more synoptic approach to GC, spreading most recent and relevant topics in the several research fronts, and contributing to disseminating the 
field. Based on these analyses, Paul Anastas is undoubtedly the main intellectual hub of GC, publishing papers that systematize the field and communicate its plurality of topics of interest. Rajender Varma and Roger Sheldon also play an important role in the dissemination of GC, especially big specialties A - Solvents and D - Catalysis (in the case of Varma), B - lonic Liquids and C - Biomass (in the case of Sheldon), and E - GC Characterization (both).

The 367 papers of the intellectual base were published between 1973 and 2017, with a total of 1,213 authorship positions, fulfilled by 816 different authors/co-authors. Eleven researchers (1\% of the total) fulfill 10\% of all authorship positions. Authors co-cited in at least two big specialties were analyzed as potential authorities for the entire field of GC. Roger Sheldon is the most published in the intellectual base, with 23 appearances (2\% of authorship positions), followed by Kenneth Seddon (1\%).

Roger Sheldon's output is the most widespread throughout the intellectual base, with 23 papers in 5 major specialties, especially D - Catalysis and E - GC Characterization. The fact that these publications are related to different specialties does not necessarily imply a consistently plural output among GC themes. It may point to a temporary shift in research, following trends of the research fronts. One way of interpreting this behavior is analyzing papers and authors that tackle themes that promote transition between two or more specialties, indicating that they do not simply belong to different specialties, but interact among themselves; this may be done by measuring BtC.

The author with the highest accumulated BtC value is Roger Sheldon, with a total of 0.5 and papers with centrality role in 4 big specialties, especially in E - GC Characterization, in which his score is 0.38 . This indicates that his output in this specialty plays an important role in interacting with other GC specialties. Paul Anastas comes in second; his papers show high BtC in big specialties D - Catalysis and E - GC Characterization; Philip Jessop has papers in 4 major specialties, excluding C - Biomass and D - Catalysis, with a focus on E - GC Characterization. Kenneth Seddon focuses his BtC only on big specialty B - Ionic Liquids, and Barry Trost focuses on E - GC Characterization. Thus, Sheldon and Jessop are the authors whose output is most widespread throughout the intellectual base of GC; they play an important role in promoting interaction among the specialties, which qualifies them as important intellectual authorities of GC. There is high concentration of high-BtC papers in cluster E - GC Characterization (5). This demonstrates the importance of this specialty in creating cohesion among the other specialties within GC.

Another interesting factor to consider in the search for the intellectual authorities of GC is peer acknowledgment; one of its indicators is the number of citations. Specifically, in the intellectual base, one can measure how many times papers were cited in the data set used for co-citation analysis - their CF. Paul Anastas is the author who accumulates the highest number of citations, with a CF value of 2,410, much higher than the runner-up, Roger Sheldon, with 1,718. Anastas concentrates his work on two major specialties, whereas Sheldon covers four, corroborating his more transversal role in the intellectual base. Tracy Williamson ranks third, with papers on D - Catalysis and E-GC Characterization. Chao-Jun Li is number 4 on the list, with papers on A - Solvents and E - GC Characterization. It is possible to see that the top three have a significant part of their accumulated CF come from papers providing support for big specialty E - GC Characterization, which reinforces the importance of this specialty in discussing the nature of GC, and providing background to the entire field of research.

Citation Burstiness analysis shows us the growth of interest in a paper by means of a sudden increase of citations, which may indicate a certain degree of innovation introduced by the authors in the specialties. Once again, Sheldon leads with the highest CB value, and a wide range of participation in specialties. Next, three authors have outputs that aroused great interest in the big specialty B - Ionic Liquids: Kenneth Seddon, Thomas Welton, and Robin Rogers. This demonstrates that ionic liquids were considered a novelty for GC, and drew an increasing amount of attention among researchers, especially between 2002 and 2009.

The above analysis shows that Roger Sheldon is the most important author of the intellectual base of GC, and a possible intellectual authority of wider scope, with a high number of papers promoting interaction among 
GC specialties, and holding a high number of citations. Sheldon's output seems to be more focused on the specific challenges of the specialties, possibly publishing useful work on the instrumentalization of GC. Another relevant author is Philip Jessop, whose papers appear in various specialties, and promote interaction among various research fronts. Surprisingly, Anastas does not act as intellectual authority for the entire field of GC. As discussed earlier, he plays a key role in disseminating the knowledge and practices of GC - an intellectual hub. Hence perhaps his high CF value on the intellectual base, even if he does not have broad participation in the specialties or high BtC. His work is important as it sets the boundaries of the field of GC, but it may not develop specific (technical) knowledge related to the specialties.

\section{Intellectual hubs and authorities throughout time}

In the first six years (1996-2001), the authors who act as intellectual hubs dealt mainly with the characterization of GC, catalysis, and solvents. The significant increase in research fronts in 1999 may have resulted from the publication of the book "Green Chemistry: theory and practice" (Anastas; Warner, 1998), which standardizes the 12 Principles for GC design, and constitutes the foundation of the Green Chemistry Journal, in 1999.

In the research fronts of the period, Kitazume cites a greater number of articles (Cov-N=16.87) and appears more often in research fronts with the theme of recycling and solvent recovery (LCS=4). Holliday, King, and List appear in the greatest number of big specialties of that period ( $\mathrm{N}$ Besp=3), addressing the characterization of GC and carbon dioxide as a substrate. Varma receives the highest number of citations (GCS), indicating the recognition of his research in catalysis. The potential intellectual authorities of the period mainly address the issue of solvents, such as Jessop and Li, who appear in 3 major specialties (N Besp), and have a high citation frequency ( $\mathrm{CF}=136$ and 112, respectively); but authorities, such as Trost, also address the characterization of GC. Welton is an important author of the period, introducing the theme of ionic liquids, which will gain importance in the following period.

Between 2002 and 2007, big specialty B - Ionic Liquids dominates among GC specialties. Among the intellectual hubs, Rogers, Holbrey, Seddon, Branco, Welton, Ritchie, Gordon, and Farmer stand out in the approach of this theme, with Rogers presenting greater coverage and greater frequency in the research fronts concentrated in only one major specialty (B - lonic Liquids). However, Swatloski has high coverage and frequency in the issue of biomass in conjunction with ionic liquids. Among intellectual authorities, Wasserscheid and Welton are widely cited for their research on ionic liquids. Seddon and Keim are other authors who approach the topic and deserve to be highlighted for their frequency of citation or mentioned production, respectively. This second period seems to be exploring the practical possibilities of GC ideas, in which ionic liquids have emerged as a promising alternative. However, the theme faced a decline in the following years.

GC achieved its expansion and greater recognition between 2008 and 2013, especially in 2010, with many published works and big specialties, and mainly focused on biomass, catalysis, and GC characterization. While in the early years it was necessary to highlight the green potential of a research, Clark et al. (2014) reports that in this period it was necessary to clarify what GC is, given the large output. This period also contrasts with the initial years of GC for the plurality of specialties, as also noted by Sheldon (2008) and Clark et al. (2014). In the early years, alternative reaction media (solvents, ionic liquids, etc.) and catalysts dominated the field, but now there is a massive presence of biomass, characterization of GC, and other sub-themes. Regarding the nature of GC, Anastas (2007) starts promoting GC as a way to innovate and generate better products (transformative nature) considering the 12 Principles in an integrated manner, differently from the early years when GC was focused on eliminating or reducing bad elements, and approaching independent principles (incremental nature). 
Among the intellectual hubs of the period, Hara (addressing biomass) and Cadierno (solvents) contributed greatly to the establishment of their specialties (high coverage and low number of great specialties). Lastra-Barrera and Crochet deal with solvents, present in several major specialties with various roles. Polshettiwar has many citations (GCS), but is present in few big specialties, indicating that he is a more specialized hub. Anastas and Eghbali receive many citations (GCS), and are present in several major specialties, indicating their role in the recognition and dissemination of GC as a whole. Among the intellectual authorities, Sheldon is co-cited in several major specialties, with the highest number of co-cited production and the highest co-citation frequency, especially addressing issues of GC characterization and catalysis. Li addresses solvents for organic reactions, having high frequency of co-citation and co-production.

The last period (2014-2017) finds GC more focused on some specialties, especially its characterization, biomass and carbon dioxide as a substrate. Sheldon (2014) had already set biomass as a third pillar of GC, along with minimizing waste and eliminating toxicity, which is corroborated in the research fronts since 2010. Marcelino, Pinto, and Marques (2020a) analyzed GC, and qualified the characterization of the field and biomass as emerging themes.

Sheldon (more focused on the GC characterization and biomass), Steinbauer, and Werner (more focused on carbon dioxide as a substrate) are potential intellectual hubs of this last period, with high coverage, and acting on the research front of 2 big specialties (out of a total of 4 big specialties in that period). Regarding intellectual authorities, Dumesic (addressing biomass) appears in several big specialties, has a higher number of co-cited papers, and high co-citation frequency.

\section{Validation of results}

In 2016, the Green Chemistry Journal published a series of 13 editorials commemorating the 25 years of GC, penned by renowned authors of the field and showcasing the advances made in each of the Twelve Principles. By crossing the authors of these editorials and their references with the results of this research, it is possible to provide indications of the relevance of the results found. Two out of the 14 different intellectual hubs wrote papers for the commemorative editorials, and two are listed in their references, so that $29 \%$ of the hubs are related to these editorials.

There are 21 different intellectual authorities, twelve of which are related to the editorials (57\%). Around 40\% of the intellectual hubs are not mentioned in the commemorative editorials. This may be due to the fact that they are more closely connected with recent and transient literature (connected to research fronts), while the editorials were focused on presenting the advancements and milestones in GC, focusing on more consolidated research programs. It should also be taken into account that the editorials were structured around principles, not specialties or research themes, which may explain why none of the hubs or intellectual authorities of big specialty B - lonic Liquids are related to the editorials, as well as account for the great participation of authors of specialty E -, GC Characterization. In brief, Chart 4 presents the most important authors in each specialty.

Chart 4. Intellectual hubs and authorities of Green Chemistry and their specialties (1990-2017).

\begin{tabular}{|c|c|c|}
\hline Specialties & Hubs & Authorities \\
\hline A - Solvents & $\begin{array}{l}\text { Victorio Cadierno } \\
\text { Javier Francos }\end{array}$ & Chao-Jun Li \\
\hline B - Ionic Liquids & $\begin{array}{l}\text { Robin Rogers } \\
\text { Kenneth Seddon }\end{array}$ & $\begin{array}{l}\text { Kenneth Seddon } \\
\text { Robin Rogers } \\
\text { Tom Welton } \\
\text { Peter Wasserscheid }\end{array}$ \\
\hline
\end{tabular}


Chart 4. Intellectual hubs and authorities of Green Chemistry and their specialties (1990-2017).

\begin{tabular}{|c|c|c|}
\hline Specialties & Hubs & Authorities \\
\hline \multirow{4}{*}{ C-Biomass } & David Alonso & James Dumesic \\
\hline & James Dumesic & George Huber \\
\hline & Atsushi Takagaki & Avelino Corma \\
\hline & Michikazu Hara & Sara Iborra \\
\hline \multirow{3}{*}{ D - Catalysis } & Rajender Varma & Rajender Varma \\
\hline & Michikazu Hara & André Loupy \\
\hline & & Vivek Polshettiwar \\
\hline \multirow{5}{*}{ E - GC Characterization } & Paul Anastas & Roger Sheldon \\
\hline & Roger Sheldon & James Clark \\
\hline & James Clark & David Constable \\
\hline & & Alan Curzons \\
\hline & & Barry Trost \\
\hline \multirow{4}{*}{$\mathrm{F}-\mathrm{CO}_{2}$ as substrate } & Johannes Steinbauer & Philip Jessop \\
\hline & Thomas Werner & Walter Leitner \\
\hline & & Toshiyasu Sakakura \\
\hline & & Jun-Chul Choi \\
\hline \multirow{2}{*}{ GC (general) } & Paul Anastas & Roger Sheldon \\
\hline & Rajender Varma & Philip Jessop \\
\hline
\end{tabular}

Source: Elaborated by the authors (2020).

Note: $\mathrm{CO}_{2}$ : Carbon Dioxide; GC: Green Chemistry.

\section{Final Considerations}

Authors in the research fronts for each specialty were found by the accumulated coverage of their outputs, generating the list of 14 researchers that act as intellectual hubs of GC specialties. As the research fronts are related to the most relevant and recent research at a given time, these intellectual hubs are majorly responsible for disseminating, sharing, and organizing a specialty around a research object. The knowledge in the research fronts is built upon knowledge previously described in the intellectual base. Highly relevant authors in the intellectual base function as intellectual authorities to their specialties.

In the early years, GC specialties were focused on alternative reaction media (reactions in aqueous media, solventless reactions, solvent recovery, ionic liquids) and catalysts. The intellectual hubs and authorities of these periods are linked to the largest research fronts of those moments. Ionic liquids were particularly prominent around 2002, but became less so in the following years. In 2010, GC had a rapid growth, with a pluralization of its specialties and increase in its sizes; the focus shifted from ionic liquids to biomass, metallic catalysis with microwave activation, and GC characterization. As of 2014, biomass, characterization of GC, and carbon dioxide as a substrate became the main research fronts.

The initial years of GC showed hubs and authorities more closely linked to specific specialties. As of 2010, with the expansion of GC, authors like Anastas and Sheldon started to play a more transversal role within the field as hub and authority, respectively. Hubs and authorities are not the only ones structuring the GC field, nor are they responsible for all the knowledge in this research branch. However, they have a special significance in founding and spreading GC practices.

This research may contribute for a better understanding of the structure of GC, assist new researchers in the field to better understand it, and help in the search for relevant information about topics of interest. Co-citation analysis was a suitable strategy for the analysis of scientific specialties, and the use of its metrics showed to be relevant for determining hubs and intellectual authorities in the field. However, the lack of author keywords in some 
journals, such as "Green Chemistry", proved to hinder the retrieval of information. Also, the changing of algorithm for Keywords Plus in Web of Science makes it difficult to retrieve the same registers nowadays. A thoughtful standardization of databases and indexation is required, and it is worth considering in future research. Comparisons with qualitative descriptions made in the field corroborate the coherence of the results of this research, and eventual discrepancies seem to reflect differences in the approach to information in the field: the analyses made by experts stem from the Twelve Principles as prior categories for the organization of GC, while this research draws specialties from the field's own citation patterns. This seems to be a more coherent strategy with the current GC goal of thinking the Twelve Principles in a comprehensive, interdependent way, as well as overcoming the incremental vision based on isolated principles.

\section{Contributors}

L. V. MARCELINO performed the data collection, statistical analysis, and drafted the first version of the manuscript. A. L. PINTO contributed to the conceptualization and data interpretation. C. A. MARQUES contributed to the conceptualization of the study, data interpretation, and editing the manuscript. All authors reviewed and approved the final version of the manuscript.

\section{References}

Anastas, P. T. Green chemistry design, innovation, solutions and a cohesive system. Green Chemistry Letters and Reviews, v. 1, n. 1, p. 3-4, 2007. Doi: http://dx.doi. org/10.1080/17518250701642852.

Anastas, P. T. et al. Happy silver anniversary: Green Chemistry at 25. Green Chemistry, v. 18, n. 1, p. 12-13, 2016. Doi: http:// dx.doi.org/10.1039/C5GC90067K.

Anastas, P. T. et al. The Green ChemisTREE: 20 years after taking root with the 12 principles. Green Chemistry, v. 20, n. 9, p. 19291961, 2018. Doi: http://dx.doi.org/10.1039/C8GC00482J.

Anastas, P. T.; Eghbali, N. Green Chemistry: principles and practice. Chemical Society Reviews, v. 39, n. 1, p. 301-312, 2010. Doi: http://dx.doi.org/10.1039/b918763b.

Anastas, P. T.; Warner, J. C. Green Chemistry: theory and practice. New York: Oxford University Press, 1998.

Araújo, C. A. A. Correntes teóricas da ciência da informação. Ciência da Informação, v. 38, n. 3, p. 192-204, 2009.

Berger-Wolf, T.; Chawla, N. Multi-Dimensional, multilayer, nonlinear and dynamic hits. In: SIAM International Conference on Data Mining, 19., 2019, Philadelphia. Proceedings Online [...]. Philadelphia: Society for Industrial and Applied Mathematics, 2019. Available from: https://epubs.siam.org/doi/book/10.11 37/1.9781611975673. Access on: May 11, 2020.

Chen, C. CiteSpace II: detecting and visualizing emerging trends and transient patterns in scientific literature. Journal of the American Society for Information Science and Technology, v. 57, n. 3, p. 359-377, 2006. Doi: http://dx.doi.org/10.1002/ asi.20317.

Chen, C. Science mapping: a systematic review of the literature. Journal of Data and Information Science, v. 2, n. 2, p. 1-40, 2017. Doi: http://dx.doi.org/10.1515/jdis-2017-0006.

Clark, J. Evolution and growth in 2001. Green Chemistry, v. 3, n. 1, p. 1, 2001. Doi: http://dx.doi.org/10.1039/b100448o.
Clark, J. H. et al. 15 years of Green Chemistry. Green Chemistry, v. 16, n. 1, p. 18-23, 2014. Doi: http://dx.doi.org/10.1039/ C3GC90047A.

Hjørland, B. Domain analysis: a socio-cognitive orientation for information science research. Bulletin of the American Society for Information Science and Technology, v. 30, n. 3, p. 17-21, 2005. Doi: http://dx.doi.org/10.1002/bult.312.

Ivanković, A. Review of 12 principles of Green Chemistry in practice. International Journal of Sustainable and Green Energy, v. 6, n. 3, p. 39-48, 2017. Doi: http://dx.doi.org/10.11648/j. ijrse.20170603.12.

Kleinberg, J. M. Hubs, authorities, and communities. ACM Computing Surveys, v. 31, n. 4, p. 1-5, 1999. Doi: http://dx.doi. org/10.1145/345966.345982.

Liao, H. et al. Ranking in evolving complex networks. Physics Reports, v. 689, p. 1-54, 2017. Doi: http://dx.doi.org/10.1016/j. physrep.2017.05.001.

Majó-Vázquez, et al. Media roles in the online news domain: authorities and emergent audience brokers. Media and Communication, v. 8, n. 2, p. 98-111, 2020. Doi: http://dx.doi. org/10.17645/mac.v8i2.2741.

Marcelino, L. V.; Marques, C. A. Trends in Green Chemistry Research. In: Annual Meeting of the Brazilian Chemical Society, 42., 2019, Joinville. Proceedings Online [...]. Joinville: SBQ, 2019. Available from: http://www.sbq.org.br/42ra/ anexos/42RASBQ_programa_e_resumos.pdf. Access on: Sep. 23, 2019 .

Marcelino, L. V.; Pinto, A. L.; Marques, C. A. Scientific specialties in Green Chemistry. Iberoamerican Journal of Science Measurement and Communication, v. 1, n. 1, 2020a. Available from: https://colnes.org/index.php/ijsmc/article/view/6. Acess on: Aug. 18, 2020.

Marcelino, L. V.; Pinto, L.; Marques, Supplementary material: intellectual hubs and authorities, and scientific specialties of

政


Green Chemistry [Data set]. Zenodo, 2020b. Doi: http://doi. org/10.5281/zenodo.4247936.

Royal Society of Chemistry. Happy silver anniversary: Green Chemistry at 25. 2016. Available from: https://pubs.rsc.org/ en/journals/articlecollectionlanding? sercode=gc\&themeid= 17fdd7fc-ff5b-46ca-ba3e-5702b2eb2231. Access on: Sep. 24, 2018.

Noyons, E. C. M. Bibliometric mapping as a science policy and research management tool. 1999. Thesis (Doctoral Quantitative Sutudies of Science) - Leiden University, Leiden, 1999. Available from: https://openaccess.leidenuniv.nl/ handle/1887/38308. Access on: Nov. 7, 2018.

Poliakoff, M. Green Chemistry: science and politics of change. Science, v. 297, n. 5582, p. 807-810, 2002. Doi: http://dx.doi. org/10.1126/science.297.5582.807.
Sheldon, R. A. Green and sustainable chemistry: challenges and perspectives. Green Chemistry, v. 10, n. 4, p. 359-360, 2008. Doi: http://dx.doi.org/10.1039/b804163f.

Sheldon, R. A. Green and sustainable manufacture of chemicals from biomass: state of the art. Green Chemistry, v. 16, n. 3, p. 950-963, 2014. Doi: https://dx.doi.org/10.1039/ C3GC41935E.

United States Environmental Protection Agency. Pollution prevention law and policies: overviews and Factsheets. Washington: US EPA, 1990. Available from: https://www.epa. gov/p2/pollution-prevention-act-1990. Access on: May 28, 2018.

Zhong, X. et al. Recommendations for mobile apps based on the hits algorithm combined with association rules. IEEE Access, v. 7, p. 105572-105582, 2019. Doi: http://dx.doi. org/10.1109/ACCESS.2019.2931756. 